\title{
Device Carcinogenic Problem
}

National Cancer Institute

\section{Source}

National Cancer Institute. Device Carcinogenic Problem. NCI Thesaurus. Code C92031.

The device's ability to trigger development of cancer. 